\title{
Prenatal diagnosis of autosomal dominant polycystic kidney disease (PKD1) presenting in utero and prognosis for very early onset disease
}

\author{
K D MacDermot, A K Saggar-Malik, D L Economides, S Jeffery
}

Department of Clinical Genetics, Royal Free Hospital School of Medicine, Rowland Hill Street, London NW3 2PF, UK

K D MacDermot

Department of Obstetrics, Royal Free Hospital School of Medicine, Rowland Hill Street, London NW3 2PF, UK

A K Saggar-Malik

Department of Medicine, St George's Hospital Medical School, Cranmer Terrace, London SW17 ORE, UK

D L Economides

Department of Medical Genetics, St George's Hospital Medical School, Cranmer Terrace, London SW17 ORE, UK $S$ Jeffery

Correspondence to: Dr MacDermot

Received 19 March 1997 Revised version accepted for publication 11 August 1997

\begin{abstract}
We describe four prenatal diagnoses in a family with autosomal dominant polycystic kidney disease. Two pregnancies were terminated following the detection of enlarged echogenic fetal kidneys with cysts. Histopathological examination confirmed the diagnosis of polycystic kidney disease. Linkage to PKD1 was obtained by the analysis of DNA from relatives in three generations and from paraffin blocks and formalin fixed fetal tissues. Prenatal DNA analysis in subsequent pregnancies identified one unaffected fetus and one fetus carrying the high risk PKD1 allelle. Information on survival and subsequent outcome of PKD cases presenting in utero was requested by this family before prenatal testing was performed.

Of 83 reported cases of ADPKD presenting in utero (excluding termination of pregnancy) or in the first few months of life, $43 \%$ died before 1 year. Longitudinal follow up of 24 children in two studies showed that $67 \%$ of survivors developed hypertension, of whom three had end stage renal failure at a mean age of 3 years.

$(\mathcal{F}$ Med Genet 1998;35:13-16)
\end{abstract}

Keywords: autosomal dominant polycystic kidney disease; fetal renal cysts; prenatal diagnosis

Autosomal dominant polycystic kidney disease $(A D P K D)$ is a common genetic disorder characterised by progressive renal cyst development, hypertension, and frequently by the development of end stage renal failure (ESRF). ADPKD is genetically heterogeneous; the PKD1 gene has been localised at 16p13.3, ${ }^{1}$ the PKD2 gene at 4q13-23, ${ }^{2}$ and the PKD3 locus remains unknown. ${ }^{3}$ PKD1 shows wide phenotypic variability which includes clinical presentation in utero. The mechanism for such early and severe expression of the disease is at present unknown, but it could include segregation of a modifying gene with inefficient DNA transcription/repair function contributed by the unaffected parent. This hypothesis is supported by the report of the same nonsense PKD1 mutation in a father and affected fetus, ${ }^{4}$ the two hit mechanism for renal cyst formation recently reported by Qian et $a l^{5}$ by the approximately $25 \%$ recurrence rate for similarly affected sibs, ${ }^{6}$ and by the low incidence of fetal presentation reported in second degree relatives in these families. ${ }^{78}$

We describe a PKD1 family, where the gene carrier father had two unilateral renal cysts at the age of 37, but two of his offspring developed renal cysts in utero. In these ADPKD families, following a diagnosis of fetal/early childhood presentation of renal cysts, prenatal testing or screening will be requested in subsequent pregnancies. Regular follow up of affected children will be necessary as the onset of complications of the disease occur early. Genetic counselling is difficult in families requesting prenatal testing following fetal presentation of $\mathrm{ADPKD}$. Fick et at reported an apparently good renal prognosis in childhood in their subjects 8,9 , and 10 , as did Zerres $e t a l^{t}$ in their cases 2.1 and 2.2, but large numbers of cases have also died in utero or in the neonatal period. ${ }^{910}$

For prenatal test counselling, the perinatal mortality was obtained from 83 previously reported cases and the prognosis of survivors was estimated from longitudinal studies of 24 children followed up by Zerres et al and Fick et $a .^{8}$

\section{Molecular analysis}

The method of Levi et $a l^{11}$ was used for DNA extraction from fetal tissue available as paraffin sections and the method of Goelz et al ${ }^{12}$ for DNA extraction from formalin fixed tissue. DNA from the appropriate family members was extracted from peripheral lymphocytes. ${ }^{13}$

All DNA markers used in this analysis were detected by PCR, with the exception of 3'HVR where Southern blotting was used. Red Hot $\mathrm{Taq}$ polymerase was used at $0.1 \mathrm{U}$ per $15 \mu \mathrm{l}$ reaction, with the manufacturer's buffer (Advanced Biotechnology) containing $1.5 \mathrm{mmol} / \mathrm{l}$ $\mathrm{MgCl}_{2}$.

Cycling conditions were as follows: for 16AC2.5 (D16S291) one minute at $94^{\circ} \mathrm{C}$, one minute at $65^{\circ} \mathrm{C}, 30$ seconds at $72^{\circ} \mathrm{C}$ for 30 cycles; for VK5 (D16S94) and KG8 (intragenic $P K D 1$ ), one minute at $94^{\circ} \mathrm{C}$, one minute at $60^{\circ} \mathrm{C}, 30$ seconds at $72^{\circ} \mathrm{C}$ for 30 cycles. Reaction products were separated on $10 \%$ PAGE and silver stained.

\section{Case reports}

The pedigree of the family is shown in fig 1 . The great grandfather (I.1) developed hypertension at the age of 33 years, had recurrent urinary tract infections, and died of renal failure at 43 years of age. The diagnosis of ADPKD was made on post mortem examin- 


\begin{tabular}{|ll|}
\hline Markers & Alleles \\
3'HVR & More than 10 \\
KG8 & $1,2,3,4$ \\
16AC2.5 & $1,2,3,4$ \\
VK5 & More than 10 \\
\hline
\end{tabular}

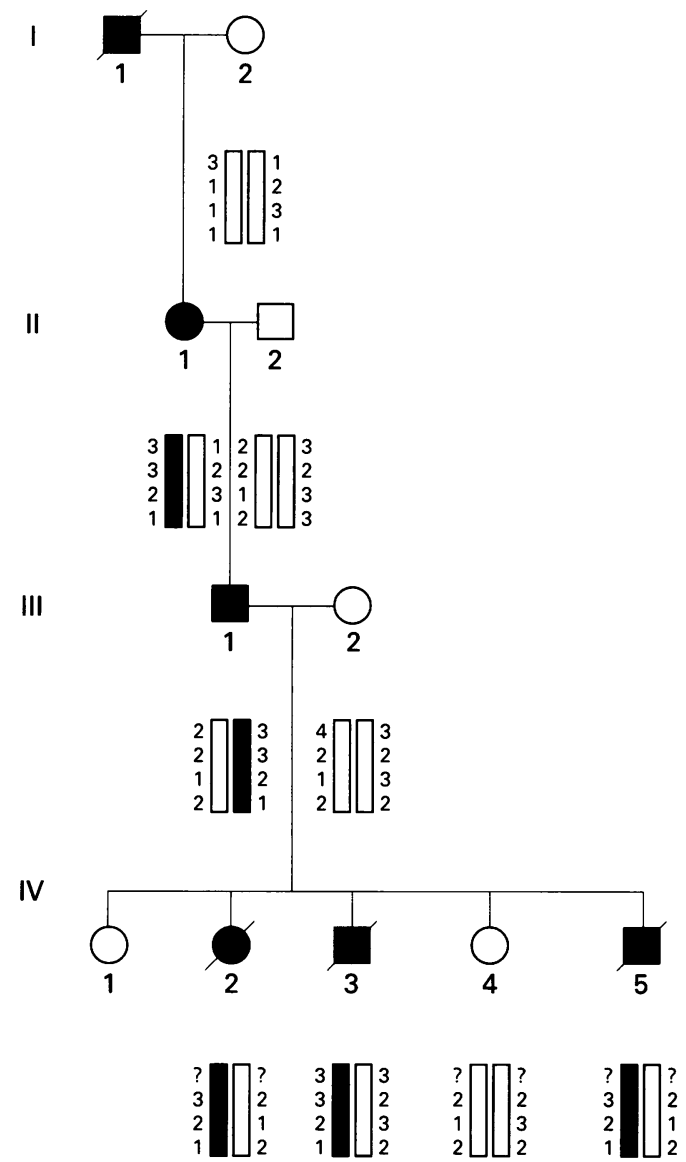

Figure 1 Pedigree showing genetic linkage to PKD1. IV.2 is case $1, I V .3$ case 2 , and IV.5 is case 3.

ation. The grandmother (II.1) presented with hypertension at the age of 55 , when she was found to have multiple bilateral renal cysts and a number of hepatic cysts. Her hypertension is controlled and she remains well, aged 72, with normal renal function. The father (III.1) of the affected fetuses is asymptomatic. At the age of 28 , renal ultrasound showed two cysts in the left kidney, but none in the right, a situation unchanged at present (aged 37). His blood pressure and renal function are normal. The mother (III.2) of the affected fetuses comes from an unrelated family with no history of ADPKD or early onset malignancies. Her brother was born with unspecified congenital heart malformation and her parents are hypertensive and had strokes in their 60s. She had a normal renal scan at the age of 35 . The first pregnancy for III. 2 resulted in a healthy girl and her renal ultrasound at 4 years was normal.

CASE 1

In the following pregnancy (IV.2), routine fetal ultrasound at 19 weeks showed bilaterally enlarged echogenic kidneys with several small cysts. Amniotic fluid volume was normal and fetal growth was consistent with gestation. At
22 weeks, oligohydramnios and fetal growth retardation developed and the pregnancy was terminated at 23 weeks. On post mortem examination, the fetus had generalised oedema, particularly of the face and lips, and a protruding abdomen filled with grossly enlarged kidneys weighing $85 \mathrm{~g}$ (normal $7 \mathrm{~g}$ ) and measuring $60 \times 35 \times 35 \mathrm{~mm}$. The ureters and the bladder were normal. On section, the kidneys had areas with multiple cysts ranging in size from 1 to $10 \mathrm{~mm}$. Microscopy showed cystic dilatation of some glomeruli and tubules admixed with others of normal appearance. No liver cysts were present and liver histology was normal.

CASE 2

In a subsequent pregnancy (IV.3), the fetal abdominal circumference and amniotic fluid volume were normal at 11 weeks, but at 16 weeks both fetal kidneys were enlarged and echogenic, each containing several small cysts. The fetal bladder was visualised and amniotic fluid volume and fetal growth were consistent with gestation. The family elected to terminate the pregnancy at 17 weeks. Histopathological examination showed cysts throughout the kidneys measuring up to $2 \mathrm{~mm}$ in diameter with no normal tissue present. On microscopy, more than 300 cystic dilatations of renal tubules and the Bowman's spaces of the glomeruli were counted on one slide.

Prenatal diagnosis was requested in the next pregnancy (IV.4) following the identification of the haplotype linked to PKD1 in this family (see results). The fetus was predicted to be unaffected, routine fetal scans were normal, and, after birth, renal ultrasound at 4 months showed normal kidneys. At 16 months, the child remains asymptomatic.

CASE 3

In the following pregnancy (IV.5), fetal scans were normal at 8 weeks and 11 weeks, when a chorionic villus sample was obtained for molecular analysis. The fetus was found to carry the high risk allele at 12 weeks (see results) and termination of pregnancy was requested and performed by suction, so that it was not possible to identify renal tissue for examination.

Normal karyotypes, in particular showing no evidence of rearrangement or microdeletion in chromosome $16 \mathrm{p}$, were confirmed in all individual samples analysed, except that of I.2, which was not done.

\section{Results}

LINKAGE TO PKD1 LOCUS

In this family, genetic linkage could only be established by the analysis of fetal tissue. On this basis, prenatal diagnosis was offered and the fetal DNA was analysed using KG8, VK5, and 16AC 2.5 markers, in addition to three informative markers on chromosomes 5,7 , and $\mathrm{X}$, to exclude maternal tissue contamination of chorionic villus samples. The material from wax embedded tissue sections was heavily degraded, producing DNA fragments below $500 \mathrm{bp}$ on agarose gels, but KG8 and VK5 
primers produced a good signal. The probe VK5 shows a recombination value of 0.01 with the PKD1 locus ${ }^{14}$ and no recombination has been reported with 16AC2.5. KG8 is in the 3' untranslated region (UTR) of the PKD1 gene. ${ }^{15}$ The pedigree and haplotypes are shown in fig 1. The 3'HVR haplotype could not be obtained for IV.2 as the DNA was too degraded and was not used for prenatal diagnoses in IV.4 and IV. 5 because of its relatively high recombination rate. A lod score of 0.9 was obtained for linkage between ADPKD and the intragenic probe KG8 in this family, using a recombination fraction of 0.001 in the calculation. Published values for the ADPKD heterogeneity in white populations range from 0.85 to $0.96 .^{16}$ When these values were applied in a Bayesian calculation, the probability of linkage to the PKD1 locus in this family was high, between 0.978 and 0.995 .

PERINATAL MORTALITY (FROM PREVIOUS REPORTS)

From 83 reported cases of ADPKD presenting in utero or in the first few months of life $^{8}{ }^{817}$ excluding termination of pregnancy (TOP), three were stillborn, 27 died $<1$ month of pulmonary or renal insufficiency or both, and six died $<1$ year of renal failure. Perinatal mortality in this group is therefore high, as a total of $43 \%$ of cases $(36 / 83)$ died before 1 year.

PROGNOSIS IN SURVIVING CHILDREN (FROM PREVIOUS REPORTS)

On reviewing the prognosis of ADPKD presenting in utero or in the first few months of life, individual reports which had variable length and mode of follow up were not included. The most informative studies were those of Fick et al, ${ }^{8}$ presenting data on follow up of 10 children (subjects 1-10) from eight families for a mean of 6.8 years, and Zerres et $a l^{\circ}$ on 14 children (cases $1.1,1.2,2.1,2.2,4.1$, $4.2,7.1,9.3,10.1,10.2,11.2,13.2,14.2,15.3$ ) from 11 families followed for a mean of five years. From 24 children diagnosed prenatally or up to 1 year of life, eight remained well (mean age of these children was 3.2 years, range 3 months to 7 years). Sixteen of 24 developed hypertension requiring treatment (at a mean age of 2.9 years, ranging from birth to 12 years; six of 16 were below the age of 6 years). ESRF developed in three hypertensive children (at a mean age of 2.8 years, range 1 to 4 years). Complications of PKD were therefore present in $67 \%$ of survivors at a mean age of 3 years.

\section{Discussion}

In this report we have shown that archival material from affected fetuses can be used for linkage analysis despite extensive DNA degradation. Since no common mutations have yet been found for PKD1, and duplication of the $5^{\prime}$ part of the gene occurs more proximally on $16 \mathrm{p},{ }^{15}$ mutation detection is at present difficult and determination of the disease locus in a family relies on genetic linkage analysis.
Linkage to the PKD2 region was not evaluated in this family. In non-PKD1 families, the onset of renal failure is later than in $\mathrm{PKDl}^{18}$ and all families with ADPKD diagnosed in utero analysed to date have shown linkage to PKD1. ${ }^{17} 1920$

The probability of linkage between the intragenic PKD1 marker KG8 and the disease in this family was 0.978 to 0.995 , which was statistically unlikely to be the result of chance. For these reasons, prenatal diagnosis by DNA was considered reliable and was offered.

Severe infantile PKD has been attributed to large deletions involving both the PKD1 gene and the adjacent tuberous sclerosis gene, TSC $2 .{ }^{21}$ Since these genes show tail to tail orientation and KG8 shows heterozygosity in the affected subjects reported here, a contiguous gene deletion is highly unlikely in this family.

In ADPKD, the incidence of development of renal cysts in utero has been estimated as $2 \%{ }^{6}$ The recurrence risk is high, with $45 \%$ of gene carrier sibs (or $25 \%$ of all sibs) showing comparable early manifestation. ${ }^{6}$ Before prenatal DNA diagnosis in this family, the parents had to make a decision whether to terminate an affected pregnancy without knowledge of the severity of the disease in the fetus. As two affected cases with in utero presentation have already occurred and the recurrence risk was $45 \%$, the parents have made the difficult decision to terminate the subsequent affected fetus.

The possible mechanisms of severe and much earlier clinical presentation of ADPKD in the fetus than in the parent are of great interest. These include anticipation, imprinting, and the segregation of modifying genes. ${ }^{82}$

Suggestive, but not conclusive data are available for anticipation and imprinting in ADPKD. ${ }^{23-25}$ Evidence for the former was presented by Fick et $a l^{23}$ who found that of 86 informative ADPKD families, 53\% showed 10 years earlier onset of ESRF in offspring, when compared to their affected parent. The clinical presentation of ADPKD in the family presented here would be difficult to reconcile with anticipation. The affected relative in generation I showed more severe clinical symptoms than his offspring in generation II, while the affected father of the cases presenting in utero was asymptomatic. The possibility of imprinting is supported by the findings of statistically significant $(\mathrm{p}<0.05)$ maternal transmission found in fetal/early childhood ADPKD onset cases (M:F 23:41) and significantly earlier onset of ESRF in subjects with ADPKD1 inheriting the disease from their mother rather than from their father ( $50.5 v 64.8$ years, $\mathrm{p}=$ $0.004) .{ }^{25}$ However, in the family reported here, the transmission was paternal. No anticipation has been observed in many families with in utero onset of the disease, which is illustrated by the family reported here and by others. ${ }^{17}{ }^{26} \mathrm{It}$ is of interest to examine the high recurrence risk for in utero presentation of PKD1, with the recent data from Qian et al. ${ }^{5}$ The authors showed that renal cysts in ADPKD are monoclonal, they have shown loss of heterozygosity for two intragenic PKD1 markers within individual cysts, and confirmed the loss of the 
normal allelle. Their report provides convincing data for a two hit mechanism in the formation of renal cysts, the same mechanism which results in loss of function in tumour suppressor genes. If this is the case, the segregation of a rare gene with inefficient DNA transcription/ repair from the unaffected parent could produce a high frequency of somatic second hits and multiple renal cysts in utero. The transmission of a modifying gene from the unaffected parent was discounted in the past by the reports of early onset $A D P K D$ in a cousin $^{90}$ and an uncle. ${ }^{27}$ As there are no other published reports (more than 160 families ) of second degree relatives with early onset $P K D$, the segregation of a modifying allele in these three families could have happened by chance. However, a very unusual transmission of early onset PKD has been reported in two additional families. In one family, the affected mother had four offspring with in utero onset PKD by two different husbands ${ }^{7}$ and, in the second family, the mother developed PKD at the age of 3 years and her offspring presented with renal cysts at 7 months. ${ }^{8}$ Theoretically, two different partners could have been carriers of a rare modifying allele by chance, but the early onset of PKD in mother and daughter does not fit this hypothesis. Both these mothers were sporadic cases and mutation analysis in these two families would be of interest.

The same stable nonsense PKD1 mutation was found in a child with fetal presentation of renal cysts as in her affected father with adult onset PKD, ${ }^{4}$ which excluded a genomic rearrangement at least in that family.

The $25 \%$ recurrence of similarly early onset PKD in sibs observed by Zerres et at would also fit with the modifying gene being inherited from the unaffected parent and this is supported by the very low incidence of in utero presentation of PKD in second degree relatives in these families.

The development of oligohydramnios in fetuses with renal cysts is regarded as an unfavourable prognostic sign. TOP is commonly performed, so that the outcome of these cases is largely unknown. Stillbirths with Potter sequence were reported in ADPKD families. ${ }^{9}{ }^{10}$ However, in one family, recurrent oligohydramnios was documented and both sibs have survived. ${ }^{26}$ One has developed ESRF at 3 months of age and the other sib had reduced renal function and short stature at 4 years, but remained normotensive.

When considering the available data regarding the prognosis of in utero presentation of PKD, it is apparent that the most useful indicator is the outcome of a previously affected sib, which shows a high degree of correlation. When the diagnosis is made in the first affected case in the family, the estimated perinatal mortality of $43 \%$ can be given with $67 \%$ of complication rate in survivors by the age of 3 years. In these cases, modifying factors determining the early development of renal cysts are likely to be present. Molecular genetic study and clinical follow up of these rare families can be accomplished by collaboration between several centres.
We are grateful to the Histopathology Department for the fetal post mortem reports. AKSM is the Williams Fellow of the University of London.

1 Reeders ST, Breuning MH, Davies KE, et al. A highly polymorphic DNA marker linked to adult polycystic kidney disease on chromosome 16. Nature 1985;317:542-4.

2 Kimberling WJ, Kumar S, Gabow PA, et al. Autosomal dominant polycystic kidney disease: localization of the second gene to chromosome 4q13-q23. Genomics 1993;18: 467-72.

3 Daoust MC, Reynolds DM, Bichet DG, Somlo S. Evidence for a third genetic locus for autosomal dominant polycystic kidney disease. Genomics 1995;25:733-6.

4 Peral B, Ong ACM, San Millan J, et al. A stable, nonsense mutation associated with a case of infantile onset polycystic kidney disease 1 (PKD1). Hum Mol Genet 1996;5:539-42.

5 Qian F, Watnick TJ, Onuchic LF, Germino GG. The molecular basis of focal cyst formation in human autosomal dominant polycystic kidney disease type 1. Cell 1996;87:979-87.

6 Zerres K, Rudnik-Schoneborn S, Deget F. Childhood onset autosomal dominant polycystic kidney disease in sibs: clinical picture and recurrence risk. German Working Group on Paediatric Nephrology (Arbeitsgemeinschaft fur Padiatrische Nephrologie). 7 Med Genet 1993;30:583-8.

7 Kaariainen H. Polycystic kidney disease in children: a genetic and epidemiological study of 82 Finnish patients. $\mathcal{f}$ Med Genet 1987;24:474-81.

8 Fick GM, Johnson AM, Strain JD, et al. Characteristics of very early onset autosomal dominant polycystic kidney disease. F Am Soc Nephrol 1993;3:1863-70.

9 Zerres K, Hansmann M, Knopfle G, Stephan M. Prenatal diagnosis of genetically determined early manifestation of autosomal dominant polycystic kidney disease? Hum Genet 1985;71:368-9.

10 Ceccherini I, Lituania M, Cordone MS, et al. Autosomal dominant polycystic kidney disease: prenatal diagnosis by DNA analysis and sonography at 14 weeks. Prenat Diagn 1989;9:751-8.

11 Levi S, Urbano-Ispizua A, Gill R, et al. Multiple K-ras codon 12 mutations in cholangiocarcinomas demonstrated with a sensitive polymerase chain reaction technique. Cancer Res 1991;51:3497-502.

12 Goelz SE, Hamilton SR, Vogelstein B. Purification of DNA from formaldehyde fixed and paraffin embedded human tissue. Biochem Biophys Res Commun 1985;130:118-26.

13 Bertelson CJ, Pogo AO, Chaudhuri A, et al. Localization of the McLeod locus (XK) within Xp21 by deletion analysis. Am f Hum Genet 1988;42:703-11

14 Hyland VJ, Suthers GK, Friend K, et al. Probe VK5B is located in the same interval as the autosomal dominan adult polycystic kidney disease locus, PKD1. Hum Genet 1990;84:286-8.

15 The European Polycystic Kidney Disease Consortium. The polycystic kidney disease 1 gene encodes a $14 \mathrm{~kb}$ transcript and lies within a duplicated region on chromosome 16. Cell 1994;77:881-94.

16 Peters DJM, Sandkuijl LA. Genetic heterogeneity of polycystic kidney disease in Europe. In: Breuning MH, Romeo G, eds. Contributions to nephrology. Basel: Karger, 1992:128-40.

17 Michaud J, Russo P, Grignon A, et al. Autosomal dominant polycystic kidney disease in the fetus. Am $\mathcal{f}$ Med Genet 1994;51:240-6.

18 Parfrey PS, Bear JC, Morgan J, et al. The diagnosis and prognosis of autosomal dominant polycystic kidney disease. N Engl f Med 1990;323:1085-90.

19 Novelli G, Frontali M, Baldini D, et al. Prenatal diagnosis of adult polycystic kidney disease with DNA markers on chromosome 16 and the genetic heterogeneity problem chromosome 16 and the ge

20 Gal A, Wirth B, Kaariainen H, et al. Childhood manifestation of autosomal dominant polycystic kidney disease: no evidence for genetic heterogeneity. Clin Genet 1989;35:13 19.

21 Brook-Carter PT, Peral B, Ward CJ, et al. Deletion of the TSC2 and PKD1 genes associated with severe infantile polycystic kidney disease - a contiguous gene syndrome. Nat Genet 1994;8:328-32.

22 Zerres K, Rudnik-Schoneborn S. On genetic heterogeneity, anticipation, and imprinting in polycystic kidney diseases. Nephrology, Dialysis, Transplantation 1995;10:7-9.

23 Fick GM, Johnson AM, Gabow PA. Is there evidence for anticipation in autosomal-dominant polycystic kidney anticipation in autosomal-dominant
disease? Kidney Int 1994;45:1153-62.

24 Gabow PA. Autosomal dominant polycystic kidney disease. N Engl f Med 1993;329:332-42.

25 Bear JC, Parfrey PS, Morgan JM, Martin CJ, Cramer BC. Autosomal dominant polycystic kidney disease: new information for genetic counselling. Am $\mathcal{F}$ Med Genet 1992;43 548-3.

26 Sinibaldi D, Malena S, Mingarelli R, Rizzoni G. Prenatal ultrasonographic findings of dominant polycystic kidney disease and postnatal evolution. Am f Med Genet 1996;65: 337-41.

27 Ross DG, Travers H. Infantile presentation of adult-type polycystic kidney disease in a large kindred. $\mathcal{F}$ Pediatr 1975 ; 87:760-3. 